\title{
Zimbabwean undergraduate nurses studying Physiology
}

\author{
Ross G. Cooper \\ Health \& Social Care, BCU, City South Campus, Birmingham B15 3TN, UK \\ Cooper RG. Zimbabwean undergraduate nurses studying Physiology. J Pre-Clin Clin Res. 2013; 7(1): 53-58.
}

\begin{abstract}
This paper investigates selected teaching/learning tools (essay, poster and exam), the experiences of learning Physiology, and peer assessment of group work activity by Zimbabwean undergraduate nursing students. Methods: Questionnaires and per observation were performed. Out of a total of 22 Zimbabwean Nursing students (2008-2009) 13 were female (59.1\%). This differed from the general expected whole class DipHE male:female ratio of ca. 10:90\%. Initially, there was a total of 7 (31.8\% of the total) Zimbabwean students who wished to participate in the exercise overall. The rest followed except for one. The reinforcing of understanding, memory and application of Physiological principles was well performed and appreciated for the design of posters. Group work would, via task apportionment, tap member's strengths and allow discussions of the areas that were poorly understood. The logical framework in a poster, referenced with pertinent papers, would enable one to determine and reflect on the individual patient's journey. As Physiology was examinable, students desired to practice MCQ questions in order to attain a gist of the exam layout. Although the usefulness and assessment of essays was excellent, students perceived them as individualistic tasks and failed to appreciate that a good essay could also be constructed via apportionment of section writing tasks to student members within a group. The use of small groups in this study allowed students to appreciate the importance of Physiological knowledge to effectively interpret clinical inter-relationships.
\end{abstract}

\section{Key words}

Learning, Teaching methods, Physiology, Zimbabwe

\section{INTRODUCTION}

Physiology is the study of the cellular functions of the organ systems in the human body. Physiology lecturers select what they teach in order that the relevant concepts and skills are acquired to help deal with clinical problems [1]. A significant correlation existed between student e-learning of Physiological processes and their final examination mark [2]. Interactive tutorials may facilitate student development of different approaches to solving problems (analysis, synthesis, trial and error, collaboration and/or accepting instructional presentations) which may be useful for studying Physiology [3]. Students can then test their own personalized models [3] (e.g. constructing an acid-secreting gastric cell) of the mechanisms underlying Physiological processes that account for data gathered in practical classes.

Students' knowledge of Physiology may be bound to situational descriptions rather than underlying principles [4]. With increasing demands on the undergraduate student to memorise large amounts of Physiological information, applications of alternative methods of learning will help re-enforce knowledge of the like and make the course more stimulating and interesting to the student. Poster assessment via buzz groups may be used to evaluate hyperlipidemic drug action (Cooper, unpublished). The assessment achieved a $100 \%$ pass rate and the positive rating of all aspects of the procedure suggested that poster presentation was a more favoured method of learning among undergraduate Physiology students (Cooper, unpublished).

There could be incumbent feelings of anxiety and high or low self-efficacy [5] in the group of Zimbabwean students

Address for correspondence: Ross G. Cooper, Health \& Social Care, BCU, City South Campus, Birmingham B15 3TN, UK

e-mail:rgcooper@hotmail.com

Received: 20 February 2012; accepted: 19 March 2013 living and studying in a foreign country, and the stresses affecting them at home and in the UK. Possible motivation for the emigration of Zimbabweans to the UK could include economic and healthcare aspects. Other issues may include education as a means of social mobility; an adverse economic crisis (with real inflation that once ran at over one quintrillion percent); the disruption of familial units by HIV/AIDS [6]; and more recently, by cholera, with a massive rise in suspected cases up to 18,413 from August - December 2008 $[7,8]$. Problems of alcohol and tobacco misuse, many of which could have been associated with economic difficulties in Zimbabwe [8] may be linked. Educational courses for nursing may be a means to prevent students' aspirations for professional occupation floundering on the current economic and political instability in Zimbabwe, rather than as a positive career choice [6]. National Health Service (NHS) funding and acceptance into a nursing programme may be suitable for the Zimbabwean student travelling on a Zimbabwean passport, as a means to apply for indefinite leave to remain.

Although students are eligible to apply for an NHS-funded study bursary, once resident in the UK for 3 years [9], many students may be forced to engage in part-time work, usually in night shifts, in order to pay their rent and provide money for their families at home in Zimbabwe [6].

Following an expensive literature search, it was revealed that there was a deficit of academic study on foreign students learning in the UK, including Zimbabweans. The current investigation was based upon the sole study of a cohort of Zimbabwean undergraduate nursing students, and not on determining differences between Zimbabwean and British students. The aim of the current research was to determine which model of learning, or combinations thereof, from a choice of essay, poster and exam were preferred by Zimbabwean nursing students. Peer assessment formed an important part of the process. 


\section{MATERIALS AND METHODS}

Design. A Zimbabwean is a social product of their language and culture, an idea substantiated by 8 dialects and numerous dialects in Zimbabwe. After leaving Zimbabwe, they share many similar experiences which include seeking a more secure future, despite their political affiliations. Action research involved the design and use of a questionnaire following the completion of tasks by the students. Action research was useful as it allowed the students to instigate the change in the method of Physiology delivery, that is, become the director of the research process [10].

Data collection. A letter of introduction was e-mailed out to 22 Zimbabwean nursing students whose names were obtained from the Academic Registry in order to ascertain willingness to participate in the study. Signed consent forms were obligatory.

Initially, a pilot test was performed on 5 Zimbabwean students selected from the second year group. The value of this was to get an idea of the inculcated experiences of learning by the Zimbabwean group. Thereafter, some questions were re-phrased so that their meaning became clearer. The pilot survey was important as it enabled every question to be unambiguous, simple and short, reasonable, and closed [11].

In the main study, initially 4 respondents replied. The study and experiences questionnaire was then e-mailed to all respondents suggesting that they print it, fill it in, and ask the Faculty of Health office to post it internally. Thereafter, following the receipt of other interested students, the data for the experiences questionnaire was completed. The final set of data from the Physiology and learning questionnaire, after completion of group tasks, was obtained for the group posters after their completion. The remaining questionnaires for group essay and exam tasks were collected. All peer and lecturer assessment forms were then completed. The letter of introduction, in addition to e-mail information, one Zimbabwean researcher, and knowledge of Physiology instruction, resulted in most of the students who were keen on methods to aid their revision, and attempt all the questions set.

Data collection techniques. Questionnaires. The purpose of the questionnaire was to satisfy the reason for the survey being performed, and how the results were used [11]. The self-administered questionnaires were distributed and the students given time to fill them in; this was a useful way of ensuring a high response rate, accurate sampling, and a minimum of interviewer bias [12].

Observations. A notebook was used to jot down significant and interesting points. This was supplemented by photographs (with permission) and completed tasks were printed. The peer/lecturer observations of group performance were bulletpointed.

Interviews. In order to minimise response-to-question leading, the investigator adopted interpretative phenomenology whereby preconceptions were used to evaluate the pros and cons of information received [10].

Literature search. The literature search for this study included:

1. Textbooks obtained from the university library - research methodology; questionnaire design; health and community surveys; product management; strategies and styles; healthcare management; change; management concepts; personnel management; theories of learning; learning and teaching in higher education; literature searches; British Society; and reviews of healthcare programmes.

2. Journal articles sourced via CD-Rom; web-based applications (library home-page: PubMed, Medline, British Education Index, Education Line, Cinahl, Inform, Eric, Healthrom, NFER and Assia); and manual searches through journal volumes, proceedings and reports.

3. Newspapers, magazines and periodicals.

4. Past MA dissertations housed in the university library.

5. Communications with the Zimbabwean community in Birmingham - personal, e-mail and telephone.

6. Communications with an academic who had previously conducted research on Zimbabwean university students in another university in the UK. Discussions prior to the research allowed the investigator to determine whether the research was theoretical, experimental and/or based on personal experience [13].

7. Notes provided by the tutors and supervisors.

Analysis of data. Results were tabulated and data analysed by the principal investigator from questionnaire responses using rating scales. Data was presented as mean $(\bar{a}) \pm S D$ standard deviation (SD) and analysed using MS-Excel 2003 and ANOVA II. Where appropriate, the Students t-test and Chi-Square $\left(\mathrm{X}^{2}\right)$ analyses were used. A value of $\mathrm{p}<0.05$ was taken as significant.

Limitations. Twenty-two Zimbabwean students participated in the study. They represented the total proportion of all undergraduate Zimbabwean students (2008-9). Of the respondents, 14 completed all tasks initially, followed later by the rest (one absconded). Despite the majority completing the questionnaires, they were not always completed together at one sitting. The researcher approached the students in a completely neutral manner in order to minimise potential bias as a consequence of previous personal history or professional contact with the students. The students in question had not been taught by the researcher.

Ethical considerations. Ethics was granted by the Faculty of Education (15/12/08) for post-graduate study, and written consent obtained throughout the study prior to the commencement of data collection and photography. Videoing of sessions was denied by the participants. The location of the study was based in areas familiar to the students (lecture rooms and libraries). An atmosphere of friendliness and interaction was fostered. All participants signed a consent form. All responses were completely confidential and the students chose to turn up and participate on a purely voluntary basis.

\section{RESULTS}

Student number. Out of a total of 22 black Zimbabwean nursing students (2008/9), 13 were female (59.1\% of the total). This differed from the general expected whole class DipHE male:female ratio of ca. 10:90\%. The specific numbers of students by country of birth in the 2008-9 DipHE run are presented in Table 1. Zimbabwe represented a substantial 
proportion of all students who were not born in the UK (Tab. 1).

Table 1. Undergraduate DipHE student numbers by country of birth (2008-9)

\begin{tabular}{lc}
\hline Country & Student numbers \\
\hline United Kingdom & 21 \\
Zimbabwe & 22 \\
Nigeria & 7 \\
Somalia & 5 \\
Ghana & 4 \\
Bangladesh & 3 \\
Cameroon & 3 \\
Jamaica & 3 \\
The Netherlands & 3 \\
Eritria & 2 \\
Germany & 2 \\
India & 2 \\
Liberia & 2 \\
Poland & 2 \\
Angola & 1 \\
Botswana & 1 \\
Czech Republic & 1 \\
Democratic Republic of Congo & 1 \\
Hungary & 1 \\
Iran & 1 \\
Ireland & 1 \\
Norway & 1 \\
Pakistan & 1 \\
Slovakia & 1 \\
South Africa & 1 \\
Thailand & 1 \\
The Gambia & 1 \\
Ukraine & 1 \\
USA & 1 \\
\hline & 1 \\
\hline
\end{tabular}

E-mail responses. Initially, 4 (18.2\% of the total) Zimbabwean students responded and duly agreed to participate in the study. They completed printed or word-completed versions of the questionnaires. The former were handed to the investigator. None were internally posted. One student refused to participate. The students were motivated as they felt that the exercises provided unique extensions to their revision, one of whom suggested more practice MCQs. There were a total of 7 (31.8\% of the total) Zimbabwean students who initially expressed their wish to participate in the exercise overall.

Reasons for study and experiences. The number of students forwarding particularly relevant or interesting responses was presented in brackets. Six students out of all respondents seemed to provide an interesting thread of ideas/arguments. The remaining responses were broadly general.

The response to question 1 (seeking the reasons why they chose a nursing course) was generally positive, especially with the focus on health and gaining a professional qualification (1 student). Others added that they liked the profession and had personal qualities favourable for nursing (4 students). Some indicated that it was vocational (1 student).

The gist of question 2 (opportunities provided by a nursing qualification) was answered principally with a focus on knowledge improvement and making one globally marketable (1 student). Another suggested that they could be employable in an NHS trust of their choice and/or private health institutes (1 student). Motivation and enhanced practice ability through knowledge was emphasised (2 students). Some advocated the opportunity to specialise (2 students).
Answers as to whether they were working part-time were varied (question 3). Some said no and rather devoted their spare time presumably to their studies and families (5 students). One said s/he was working bank shifts in community care homes.

In discussing whether efficient support mechanisms were in place (question 4), students indicated that they were allowed effective time management and the opportunity to receive extra lessons and/or attend workshops (3 students). Others emphasised the advantages of IT and numeracy drop-in centres, personal development centres, provision of assignment tutorials and library facilities (3 students).

Question 5, being two-tiered, received detailed answers. Not everybody put forward answers to the respective questions. Part a) discussing that the knowledge gained assisted with practical situations, demonstrated that a student felt that teaching motivated them to read, research and revise more. Another wrote that he/she was better able to link the theory of learning outcomes with practice. In Part b) the knowledge gained enabled one student work more effectively in groups. One suggested that it enabled a closer interaction with practice assessors in seeking help and advice. Another pointed to an ability to reflect more often (1 student). Importantly, one other wrote that it would make them a successful nurse. One student said they would become more applied. Another said it would make them more confident, allow more responsibility and facilitate promotion.

Question 6, in consideration of critical thinking, resulted in some comprehensive answers. For instance, the course, being an applied science, and the chance to study detailed Anatomical and Physiological associations, allowed one to be thoughtful in the observation of patients and diagnosis of disease (1 student). Another wrote that by getting involved in critical reflective writing, assignments and critical analysis, they could better deduce the link between theory and practice (1 student). Another student emphasised that it allows them to better demonstrate their understanding of knowledge, and put it into practice (1 student). The allowance of research was one outcome of critical thinking (1 student). Interestingly, one wrote that critical thinking allowed them to become more aware of drug errors and avoid lapses to prevent unnecessary death (1 student).

Experiences. Numerical responses to questions are documented in Table 2. In some cases, students left questions unanswered. We assumed that this was because they were not precisely relevant to them. The highest response data was placed in bold font.

Physiology and learning. Counts to questions were written down in Table 3. In some cases, some students left questions unanswered. There was no stipulation that they had to answer every single question. The highest counts were shown in bold.

Teaching/learning tools. A group of 5 students $(22.7 \%$ of the total) initially met to complete the entire task and evaluate one another's presentations. Once enlightened, the majority of students wished to participate. A pre-booked study room in the campus library was used.

Group essay. Initially, 5 students met with the investigator in a study room of the university library and completed a group task on the Physiological aspects of the cell, organelle 
Table 2. Experiences of studying Physiology.

\begin{tabular}{|c|c|c|c|c|}
\hline Question/response & $\begin{array}{l}\text { Excel- } \\
\text { lent }\end{array}$ & Good & $\begin{array}{l}\text { Neu- } \\
\text { tral }\end{array}$ & Bad \\
\hline Coping, sleep, health and nutrition & 1 & 4 & 1 & 0 \\
\hline Stress and apprehension & 1 & 3 & 2 & 0 \\
\hline Impact of external stressor on concentration & 1 & 1 & 3 & 0 \\
\hline Enthusiasm for the course & 6 & 0 & 0 & 0 \\
\hline Social networks & 2 & 4 & 0 & 0 \\
\hline Depth of teaching of subjects & 5 & 1 & 0 & 0 \\
\hline Provision of a teaching laboratory & 4 & 1 & 0 & 0 \\
\hline Provision of handouts and notes & 3 & 3 & 0 & 0 \\
\hline Support from IT & 3 & 3 & 0 & 0 \\
\hline $\begin{array}{l}\text { Computer-assisted and web-based learning } \\
\text { (Moodle, ‘CDs) }\end{array}$ & 5 & 1 & 0 & 0 \\
\hline Provision and availability of textbooks & 5 & 1 & 0 & 0 \\
\hline Group size & 3 & 3 & 0 & 0 \\
\hline Coping strategies to study & 3 & 3 & 0 & 0 \\
\hline $\begin{array}{l}\text { Understanding of examination format (MCQ and } \\
\text { Structured) }\end{array}$ & 3 & 3 & 0 & 0 \\
\hline Provision of quizzes & 5 & 1 & 0 & 0 \\
\hline Value of research papers to learning & 4 & 1 & 0 & 0 \\
\hline Volume of work to read & 3 & 2 & 0 & 0 \\
\hline Difference from GCSE/A-Level & 3 & 2 & 0 & 0 \\
\hline Frequency of lectures and practical sessions & 5 & 0 & 0 & 0 \\
\hline Ability to link various subjects in Physiology & 4 & 1 & 0 & 0 \\
\hline Ability to retain information & 3 & 1 & 1 & 0 \\
\hline $\begin{array}{l}\text { Motivation from fellow students and study } \\
\text { partners }\end{array}$ & 2 & 3 & 1 & 0 \\
\hline Enjoyment of Physiology & 4 & 2 & 0 & 0 \\
\hline Relevance of practical sessions in Physiology & 4 & 2 & 0 & 0 \\
\hline Association of Physiology theory with practice & 4 & 2 & 0 & 0 \\
\hline The use of a variety of teaching resources & 3 & 3 & 0 & 0 \\
\hline Availability of organ models & 3 & 2 & 1 & 0 \\
\hline Tutorial support & 4 & 2 & 0 & 0 \\
\hline Approachability of lecturers & 5 & 1 & 0 & 0 \\
\hline Encouragement of class discussion & 5 & 1 & 0 & 0 \\
\hline $\begin{array}{l}\text { Assistance forthcoming from tutors during } \\
\text { practicals }\end{array}$ & 3 & 3 & 0 & 0 \\
\hline Preparation provided for examination & 5 & 1 & 0 & 0 \\
\hline Long-term usefulness to career in nursing & 3 & 3 & 0 & 0 \\
\hline Clinical significance & 4 & 2 & 0 & 0 \\
\hline TOTAL & 123 & 66 & 9 & 0 \\
\hline $\mathrm{p} ; \mathrm{X}^{2}<0.05$ (significant) & $<0.05$ & & & \\
\hline
\end{tabular}

inclusions (nucleus, mitochondria, ribosomes, lysosomes and the membrane), cell division, cell functions, transport across a cell membrane, cell division and cancer. Students were rather quiet at the beginning, but with prompting and the use of illustrations combined with sheets of paper for discussing processes, such as diffusion and osmosis, they began to willingly discuss the topics.

An initial group of 3 students (13.6\% of the total) completed the essay task. The group essay was delivered in 2 topics respiration, and nerves and hormones. It was well-laid out in point form and clear to follow. The software package (MS-Px) used enabled the drawing of illustrations, most of which were
Table 3. Counts for demographics and teaching/learning tools.

\begin{tabular}{|c|c|c|c|c|c|c|}
\hline \multicolumn{7}{|l|}{ Demographics } \\
\hline \multirow[t]{2}{*}{ Age (years) } & $11-20$ & $21-30$ & $31-40$ & $41-50$ & $51-60$ & \\
\hline & 0 & 3 & 4 & 1 & 0 & \\
\hline \multirow[t]{2}{*}{ Gender } & Male & Female & & & & \\
\hline & 2 & $5^{*}$ & & & & \\
\hline \multirow[t]{2}{*}{ Marital status } & Single & Married & $\begin{array}{c}\text { Living } \\
\text { together }\end{array}$ & r Separated & Divorced & Bereaved \\
\hline & 2 & 3 & 0 & 2 & 1 & 0 \\
\hline \multirow[t]{2}{*}{ Religion } & Christian & Muslim & Jewish & Hindu & Sikh & Other \\
\hline & $6^{*}$ & 0 & 0 & 0 & 0 & 0 \\
\hline \multirow[t]{2}{*}{ Ethnicity } & White & Black & Asian & Chinese & Other & \\
\hline & 1 & $5^{*}$ & 0 & 0 & 0 & \\
\hline \multicolumn{7}{|l|}{${ }^{*} p<0.05$} \\
\hline \multicolumn{7}{|c|}{ Teaching/learning tools } \\
\hline & & 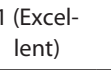 & $\begin{array}{c}2 \\
\text { (Good) }\end{array}$ & $\begin{array}{c}3 \\
\text { (Neutral) }\end{array}$ & $\begin{array}{l}4 \text { (Satis- } \\
\text { factory) }\end{array}$ & $\begin{array}{c}5 \\
\text { (Poor) }\end{array}$ \\
\hline \multicolumn{7}{|l|}{ ESSAY } \\
\hline Usefulness & & $6^{*}$ & 0 & 0 & 0 & 0 \\
\hline Group work & & 3 & 3 & 0 & 0 & 0 \\
\hline Assessment & & $6^{*}$ & 0 & 0 & 0 & 0 \\
\hline \multicolumn{7}{|l|}{ POSTER } \\
\hline Linkage & & $\mathbf{8}^{*}$ & 0 & 0 & 0 & 0 \\
\hline Memory & & $7^{*}$ & 1 & 0 & 0 & 0 \\
\hline Group work & & $7^{*}$ & 1 & 0 & 0 & 0 \\
\hline \multicolumn{7}{|l|}{ EXAM } \\
\hline Study & & $4^{*}$ & 1 & 0 & 0 & 0 \\
\hline Preparation & & $4^{*}$ & 1 & 0 & 0 & 0 \\
\hline Understanding & & $5^{*}$ & 0 & 0 & 0 & 0 \\
\hline
\end{tabular}

${ }^{*} \mathrm{p}<0.05$

$X^{2}<0.05$ (significant)

workable although simple. They used the mouse to draw. The sequestration of events beginning with the general function of an organ and the overall principal made the introduction very interesting. Students engaged in an exceptionally good discussion of inherent concepts with a simple, but effective focus on relevant Physiological drivers. There was, however, neither a conclusion nor a summary.

The group essay on the cell was discussed by groups of 2 students. The notes presented, however, were not of a high standard and appeared rushed, with untidy writing, vague statements and numerous spelling mistakes.

Group poster. Initially, 3 of the respondents completed the group essay and poster questionnaire. Thereafter, 5 students unanimously selected the heart as an organ for poster discussion. This was followed later by the remaining students. The discussion featured a basic discussion of the heart's anatomy and the routes of blood flow. The names of the pulmonary artery and vein, and the values plus the electrical conduction of the heart were emphasised. Students were given analogies to assist their understanding, e.g. the sino-atrial node being similar to a battery or generator, and the electrical system of the heart been akin to copper wires conducting electricity. The differences between the 2 types of blood circuits (pulmonary and systemic) were discussed. The tasks were tackled in pairs or by consensus in a group of 5 . The notes presented by a particular group had some important points derivable, such as the equation for cardiac output. 
Group exam (MCQ \& Structured). In pairs, the students attempted 20 MCQs followed by 5 short-answer questions. Most of them commented on how useful such an exercise was to their learning and it raised very valuable discussions on examination technique. Given the time in their exam, it was calculated that they could only spend $1 \mathrm{~min} 23 \mathrm{sec}$ on each MCQ (total of 50 questions; 1 hour exam). Most students correctly answered the MCQs. The short-answer questions provided useful revision discussions. Some students raised more queries from questions they had downloaded from Moodle, particularly on temperature.

Assessment of groups' performance. There was insufficient time for the students to peer-assess each other's work. Time was made, however, for further group work specifically during which peer and lecturer assessment could take place. In consideration of the heart presentation, the evaluation was principally positive with an appreciation of the diagrammatic representation, the mechanics of circulation, Physiological equations for cardiac output, and diseases. The queries raised by the other student groups were of a high standard.

\section{DISCUSSION}

This paper reported an exploration of student experience in using some specific learning methods in 21 Zimbabwean nursing students.

A response rate of $31.8 \%$ was in the agreeable range of 30 $50 \%$ as a reasonable response rate [14]. The $100 \%$ participation among the initial 7 students who engaged in interviews fitted in adequately with the reasonable expected response rate of $50-70 \%$ [14]. The feasibility of delivery and collection of data was satisfactory as the study was conducted within the remits of the university campus. The researcher, therefore, did not have to worry about travel, clerical, and support roles from appointed assistants.

The qualitative and quantitative data collected from the questionnaire and peer assessment study suggested that the questions asked were not difficult to answer, and were consistent with the students' expectations. The data gathered could certainly guide the selection of a smaller, more focused set of investigations that may serve as the basis of more extensive validation research.

The largest non-domiciled students (Zimbabweans) were an indication of the usefulness of the course for the furtherance of training, stay in the UK, and securing a job with a steady income. Zimbabweans send money home to relatives.The political and economic situation in Zimbabwe may have seen a substantial increase in emigration to the UK. This may possibly explain the lower numbers of nursing applicants from other African countries (e.g. Nigeria, Somalia and Ghana) where there is apparently less economic turmoil.

The e-mail responses showed some deficiencies, possibly as a consequence of caution, lack of time and personal choice. Attendance, although initially poor, improved after the students realised the overall benefits to their revision by participating in the tasks set. There was keenness expressed for instruction in Physiological comprehension and memory. This suggested that Physiology was possibly a challenging subject, necessitating extra help.

A collective response about this (questions 1, 3 and 4) suggested that the students had thought carefully about their personal competences and aligned these towards satisfaction of their career aspirations to become nurses. Indeed, they felt that such a path was more rewarding and secure. It was surprising, therefore, that question 2 received only 1 answer about becoming globally desirable. Knowledge was clearly aligned with opportunities to specialise. Given the desire to become nurse-trained, most of the students indicated that they applied themselves to their studies, although it could conceivably be said that the women had to devote a substantial amount of time at home and to their families. The students generally found that the assistance provided by the university was sufficient and useful to facilitate them to become globally marketable. Missing gaps in answers to question 5 were not substantiated by student enquiries. Idea comfort zones were evident and individualistic. If more students had participated in the task, a clearer degree of association may have been achieved. Question 6 achieved the greatest degree of unique response that espoused upon their motivation to help people, fully aware that this required competence achievable from skills and knowledge acquisition. Indeed, knowledge alone made one a theoretician; when combined with skills it fostered efficiency.

The experiences of studying Physiology based upon questions adopted from the literature received an overwhelming excellent rating. It was, however, not clear on what basis the students rated this. For example, was this based upon their experiences at home, or in other workplaces in the UK? Some students (not all) who found certain questions irrelevant did not attempt to answer them. This suggested personal confidence in them and did not suggest any perceived ignorance. The course was not overly taxing and allowed the students to take care of their health, despite being stressed and apprehensive. Enthusiasm for the course was significant.

Social networks were probably good among peers registered on the course. This presumably assisted with the attainment of a correct depth of knowledge. Moodle, although useful, probably needed more IT assistance and support, particularly at the beginning of the course.

Effective strategies developed to cope with the workload were essential if attainment of knowledge and effective examination techniques were used in combination to pass the assessment. It can be inferred that the considerable volume read was appreciated if research articles were provided, especially considering that the Physiology curriculum was new to them. The body's organs clearly do not operate in isolation, necessitating an ability to link their functions. However, the volume of work meant that unless students applied themselves they would struggle. Enjoyment of Physiology may have been enhanced through greater peer motivation. Practice sessions enabled a precise association of theory and practice. It would be vastly more useful to one's learning if more organ models were used. If they had learning difficulties, the Zimbabwean students felt that the lecturers were mostly approachable, and the provision of tutorial support commendable. However, they suggested that during practical sessions, tutors should be more forthcoming. The examination preparation seemed adequate, although it was obviously incumbent upon the lecturer to constantly provide tips on answering past questions during session deliveries. Knowledge of Physiology enabled one to understand the basis of disease. Overall, the Zimbabwean students appreciated the provision of learning items provided. 
The age range of $31-40$ was not unusual given that Zimbabweans, having left their homes and careers, had entered a new country hoping to get settled, one way of which included embarking on nurse training. The Zimbabwean students considered a career in nursing as a career for females. The data for marital status was mostly evenly spread, although separation and divorce was rated at 37.5\%. Although there are many reasons for marriage dissolution, one could be the increased strain from culture clash in society. All respondents admitted that they were Christian. Zimbabwean schools were based on enforced Christian principles, and it was seen as desirable and acceptable to go to church.

\section{CONCLUSION}

Reinforcement of understanding, memory, and application of Physiological principles was clearly well-performed and appreciated in the design of posters. Group work would, via task apportionment, tap on member's strengths and allow further discussion of topics. The logical framework in a poster, referenced with pertinent papers, would enable one to determine and reflect on the individual patient's journey. As Physiology was examinable, students desired the practice of MCQ questions to gain a gist of exam structure. Although the usefulness and assessment of essays were rated overwhelmingly in the excellent category, students thought that their completion was principally individualistic. They did not appreciate that a good essay could also be constructed via apportionment of section writing tasks among the members in a group.

\section{Acknowledgements}

Grateful thanks are extended to all the Zimbabwean student participants. The university library staff were helpful and granted access to the allocated study space. S. Walker provided some suggestions.

\section{REFERENCES}

1. Rangachari PK. Back to the future? Active learning of Medical Physiology in the 1900s. Adv Physiol Educ. 2007; 31: 283-287.

2. Dantas AM, Kemm RE. A Blended Approach to Active Learning in a Physiology Laboratory-Based Subject Facilitated by an e-learning component. Adv Physiol Educ. 2008; 32: 65-75.

3. Weaver DA, Petrovic T, Dodds A, Harris PJ, Delbridge LM, Kemm RE. Interactive tutorials designed to encourage deeper learning practices. In: Making new connections: ASCILITE. Proceedings of the 1996 annual conference. Australian Society for Computers in Learning in Tertiary Education (ASCILITE), University of South Australia, Melbourne 1996., Available at: http://www.ascilite.org.au/conferences/adelaide96/ papers/29.html (accessed on 19 April 2010).

4. Saunders M, Lewis P, Thornhill A. Research Methods for Business Students. Pitman Publishing, London 1997.

5. Dunn L. Theories of Learning. Learning and Teaching Briefing Papers Series. Oxford Centre for Staff and Learning Development OCSLD. Oxford Brookes University, Oxford 2002.

6. Dyson S. The life history experiences of Zimbabwean students studying pre-registration nursing in a UK university. PhD thesis, Faculty of Health and Life Sciences, School of Nursing and Midwifery, De Montford University \& University of Leicester, Leicester 2004 ..

7. ALAlami U, Cooper RG. Fatal infection in an ailing nation, The National, December 23 2008. Available at: http://www.thenational.ae/ article/20081218/FRONTIERS/932579042/1036/NATIONAL (accessed 19 April 2010).

8. Cooper RG. Learnings from young adults addicted to alcohol and/or tobacco in Zimbabwe. Addiction News 2008; 40: 2-3.

9. Overseas Applicants to Diploma Level Nursing and Midwifery Courses - Changes to Bursary Eligibility Rules. Department of Health, London 2008.

10. Descombe M: The Good Research Guide: For Small-Scale Social Research Projects ( $3^{\text {rd }}$ edn.), Open University Press, Maidenhead 2007.

11. Lutz W, Chalmers J, Hepburn W, Lockerbie L. Health and Community Surveys, vol. II. A practical manual for health and community workers. Macmillan, London 1992.

12. Oppenheim AN: 1992. Questionnaire Design, Interviewing and Attitude Measurement. Pinter Publishers, London 1992.

13. Wisker G: The Postgraduate Research Handbook ( $2^{\text {nd }}$ edn.), Palgrave MacMillan, London 2008.

14. Saunders M, Lewis P, Thornhill A. Research Methods for Business Students. Pitman Publishing, London 1997. 